\title{
Studi Pengaruh Penambahan Binder Thermoplastic Ldpe dan Pet Terhadap Sifat Mekanik Komposit Partikulat untuk Aplikasi Material Bangunan
}

\author{
Dwiki Pratama Putra, Sigit Tri Wicaksono, Amaliya Rasyida, Ridho Bayuaji \\ Departemen Teknik Material \& Metalurgi, Fakultas Teknologi Industri, Institut Teknologi Sepuluh \\ Nopember (ITS) \\ e-mail : sigit@mat-eng.its.ac.id
}

\begin{abstract}
Abstrak-Sampah plastik telah lama menjadi permasalahan kota-kota besar, tidak hanya di Indonesia namun juga di dunia. Sampah plastik sangat sulit untuk teruraikan secara alami. Plastik banyak digunakan di seluruh dunia karena memiliki beberapa keunggulan sifat di antaranya adalah ketahanan korosi yang baik, berat yang ringan, flexibel, dan isolator panas dan listrik yang baik. Tujuan penelitian ini adalah membuat material komposit dengan binder thermoplastic dari sampah plastik LDPE dan PET yang biasa ditemukan dalam bungkus makanan dan botol air mineral serta agregrat pasir yang memenuhi kriteria untuk aplikasi material bangunan. Pengujian yang dilakukan meliputi SEM, FTIR, kompresi, bending, absorbability, dan densitas. Penambahan binder thermoplastik cenderung meningkatkan sifat mekanik material komposit. Didapatkan Kekuatan kompresi maksimal sebesar 15,68 MPa pada komposit dengan komposisi binder sebesar $45 \%$. Komposit yang dihasilkan memenuhi kriteria untuk beton ringan struktural dan paving block jenis C dan D.
\end{abstract}

Kata Kunci-Sampah plastik, LDPE, PET, Komposit, Material Bangunan.

\section{PENDAHULUAN}

$\mathrm{S}_{\mathrm{y}}^{\mathrm{A}}$ AMPAH telah menjadi permasalahan lingkungan hidup yang dihadapi oleh masyarakat Indonesia dan dunia. Setiap manusia di dunia setiap harinya membuang sampah ke lingkungan dengan jenis yang berbeda-beda. Dari berbagai jenis sampah yang dibuang tersebut plastik masih menjadi penyumbang terbesar sampah di dunia. Manusia membuang sampah plastik ke lingkungan dalam bentuk kantong plastik, botol minuman, sisa produk rumah tangga, dan lain-lain. Jika tidak dikelola secara serius, pencemaran sampah jenis ini akan sangat berbahaya bagi kelanjutan planet bumi.

Kota-kota di dunia menghasilkan sampah plastik 1,3 miliar ton setiap tahunnya. Menurut perkiraan Bank Dunia, jumlah ini akan bertambah hingga 2,2 miliar ton pada tahun 2025. Diperkirakan pada tahun 2013 manusia di dunia memproduksi sampah plastik sebanyak 299 juta ton. Di Indonesia plastik juga menjadi masalah yang belum ditemukan solusi efektif nya. Indonesia menjadi negara penghasil sampah plastik terbesarkedua di dunia setelah Cina dengan produksi sampah plastik sebesar 65 juta ton per tahunnya.
Dari berbagai macam jenis plastik, plastik yang paling banyak dibuang ke lingkungan adalah jenis Polyethylene (Low Density dan High Density) dan juga PET (Polyethylene Terephtalate) yang bias anya dalam bentuk kantong plastik dan botol plastik. Plastik memiliki beberapa sifat keunggulan yaitu tahan korosi, tahan lama, isolator yang baik, murah, dan fabrikasi yang mudah [1].

Beberapa potensi bahan bangunan yang dapat diproduksi dengan bahan plastik adalah beton, paving block, ubin, genteng, dan dinding. Bahan bangunan dapat dibuat dari material komposit dengan menggunakan bahan plastik sabagai binder [2]. Diharapkan melalui adanya riset dalam pengolahan limbah plastik menjadi material bangunan ini dapat mengurangi jumlah plastik yang ada dalam skala yang besar. Dan diharapkan juga dengan adanya riset tentang pengolahan limbah plastik menjadi material konstruksi ini dapat dijadikan insipirasi dan referensi yang baik untuk orang-orang atau perusahaan yang dapat menciptakan industri pengolahan limbah plastik yang memiliki banyak manfaat.

\section{METODE PENELITIAN}

\section{A. Material}

Material yang digunakan adalah sampah plastik Low Density Polyethylene (LDPE) dan Polyethylene Terephtalate (PET) yang telah dibershikan dan dicacah. Serta agregat berupa pasir.

\section{B. Preparasi spesimen}

Pengolahan sampah plastik LDPE dan PET dengan mencuci lalu mencacah menggunakan mesin pencacah. Metode pembuatan komposit ini menggunakan metode blending. Terdapat 8 komposisi dalam percobaan ini yang ditunjukkan pada Tabel 1.

Plastik LDPE dan PET yang telah meleleh dicampur dengan pasir lalu diaduk secara merata lalu dituangkan kedalam cetakan sebelum campuran mengeras sehingga penuangan menjadi sulit. Pembuatan cetakan untuk uji bending menggunakan seng yang dibentuk dengan dimensi $127 \times 12,7 \times 3$ mm. Untuk uji kompresi spesimen dituang ke dalam cetakan dengan dimensi $5 \times 5 \times 5 \mathrm{~cm}$. Untuk pengujian serap air, densitas, SEM, dan FTIR digunakan spesimen sisa potongan pengujian kompresi dengan ukuran yang sesuai dengan yang dibutukan. 
Tabel 1.

Komposisi Material Komposit

\begin{tabular}{cccc}
\hline \hline \multirow{2}{*}{ No. } & \multicolumn{3}{c}{ Komposisi (\%wt) } \\
\cline { 2 - 4 } & LDPE & PET & Pasir \\
\hline 1 & 10 & 20 & 70 \\
2 & 20 & 15 & 65 \\
3 & 30 & 10 & 60 \\
4 & 40 & 5 & 55 \\
5 & 45 & - & 55 \\
6 & - & 45 & 55 \\
7 & 100 & - & - \\
8 & - & 100 & - \\
\hline \hline
\end{tabular}

\section{Pengujian bending}

Pengujian bending dilakukan untuk mendapatkan informasi kekuatan material ketika dibengkokkan. Pengujian kelenturan dilakukan dengan metode three point bend, dengan cara spesimen diletakan pada kedua tumpuan dan dilakukan pembebanan di tengah spesimen. Pengujian dilakukan menggunakan mesin uji bendingn di Universitas Airlangga Surabaya. Prosedur pengujian menurut standar ASTM D790. Dimensi spesimen yang diuji sesuai standart tersebut ialah sebesar $127 \times 12.7 \times 3 \mathrm{~mm}$.

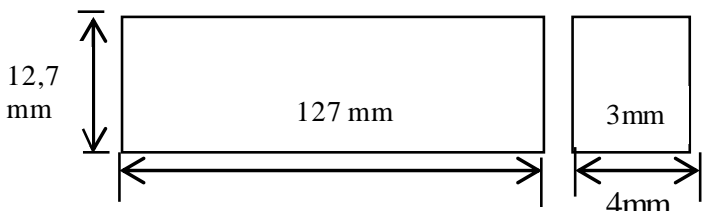

Gambar 1. Dimensi spesimen uji bending

Kekuatan lentur suatu material dapat dihitung denga persamaan berikut:

$$
\sigma_{\mathrm{f}}=\frac{3 \mathrm{PL}}{2 \mathrm{bd}^{2}}
$$

Keterangan :

$\sigma_{\mathrm{f}}=\operatorname{Kekuatan} \operatorname{Lentur}\left(\mathrm{Kg} / \mathrm{cm}^{2}\right)$

$\mathrm{L}=$ Support span $(\mathrm{cm})$

$\mathrm{P}=$ Beban patah $(\mathrm{Kg})$

$\mathrm{b}=$ lebar spesimen $(\mathrm{cm})$

$\mathrm{d}=$ tebal spesimen $(\mathrm{cm})$

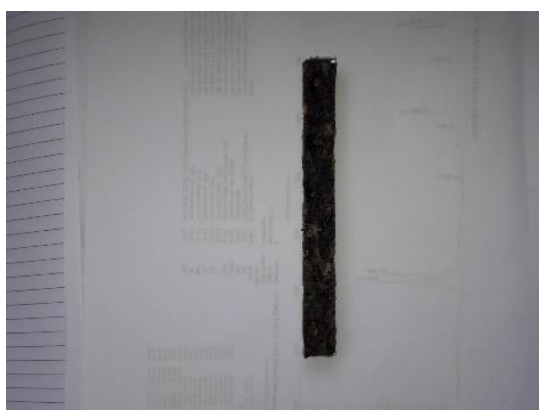

Gambar 2. Spesimen uji bending

\section{Pengujian Kompresi}

Pengujian kompresi dilakukan untuk mengetahui kekuatan kompresi dari material komposit. Bahan bangunan memiliki kekuatan kompresi minimal untuk menahan tegangan yang diterima. Dengan mengetahui kekuatan kompresi material komposit yang telah dibuat, kita dapat mengetahui aplikasi yang cocok untuk setiap material komposit yang telah dibuat. Dimensi spesimen yang dibuat untuk pengujian kompresi adalah $5 \times 5 \times 5 \mathrm{~cm}$.

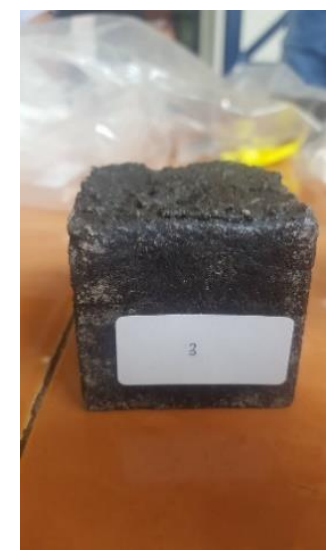

Gambar 3. Spesimen uji kompresi

\section{E. Pengujian Densitas}

Pengujian dilakukan dengan perhitungan massa spesimen dalam udara dan air masing-masing spesimen komposit menggunakan standard ASTM D792.

\section{F. Pengujian Absorbability}

Pengujian absorbability dilakukan dengan menghitung perubahan berat dari suatu agregat akibat air yang menyerap ke dalam pori di antara partikel pokok dibandingkan dengan pada saat kondisi kering, ketika agregat tersebut dianggap telah cukup lama kontak dengan air sehingga air telah menyerap penuh. Standar laboratorium untuk penyerapan akan diperoleh setelah merendam agregat yang kering ke dalam air selama $(24+4)$ jam. Agregat yang diambil dari bawah muka air tanah akan memiliki nilai penyerapan yang lebih besar bila tidak dibiarkan mengering. Sebaliknya, beberapa jenis agregat mungkin saja mengandung kadar air yang lebih kecil bila dibandingkan dengan yang pada kondisi terendam selama 15 jam.

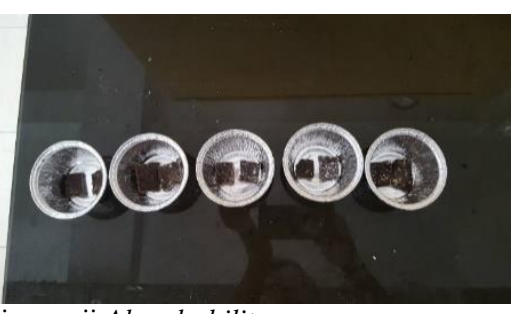

Gambar 4. Spesimen uji Absorbability

Untuk agregat yang telah kontak dengan air dan terdapat air bebas pada permukaan partikelnya, persentase air bebasnya dapat ditentukan dengan mengurangi penyerapan dari kadar air total. 


\section{G. Scanning Electron Microscopy (SEM)}

Morfologi dari spesimen komposit ditunjukkan dengan fotomikrograph Scanning Electron Microscope. Selain morfologi, melalui fotomikrograph SEM juga bisa didapatkan informasi persebaran porositas, dan ukuran porositas. SEM menganalisa interface antara binder thermoplastik dan agregat berupa pasir.

Pengamatan morfologi dilakukan di Jurusan Teknik Material dan Metalurgi Fakultas Teknologi Industri Institut Teknologi Sepuluh Nopember Surabaya dengan perbesaran sebesar $45 \mathrm{x}$ dan 500x.

\section{H. Pengujian FTIR}

Pengujian dengan alat FTIR dilakukan untuk menemukan gugus fungsi dari material komposit dan membangdingkan dengan gugus fungsi dari material penyusunnya yaitu LDPE dan PET. Pengujian FTIR dilakukan dengan mesin FTIR milik Jurusan Teknik Material dan Metalurgi FTI ITS

\section{HASIL DAN PEMBAHASAN}

\section{A. Pengujian bending}

Dari hasil pengujian dengan adanya penambahan binder thermoplastik dalam komposit mempengaruhi nilai kekuatan bending dari komposit tergantung dari banyaknya komposisi binder thermoplastik pada komposit. Kekuatan bending ditunjukkan pada Tabel 2.

Tabel 2.

Hasil uji bending

\begin{tabular}{cccc}
\hline \hline No. & $\begin{array}{c}\text { Binder } \\
(\% \text { wt })\end{array}$ & $\begin{array}{c}\text { Agregat Pasir } \\
(\% \mathrm{wt})\end{array}$ & $\begin{array}{c}\text { Kekuatan } \\
\text { Lengkung } \\
(\mathrm{MPa})\end{array}$ \\
\hline 1 & 30 & 70 & 46,02 \\
\hline 2 & 35 & 65 & 85,46 \\
\hline 3 & 40 & 60 & 53,82 \\
\hline 4 & 45 & 55 & 148,55 \\
\hline \hline
\end{tabular}

Kekuatan bending paling tinggi didapatkan dengan komposisi 45\%wt binder thermoplastik dan 55\%wt pasir dengan kekuatan kompresi sebesar 148,55 MPa. Sedangkan nilai kekuatan bending paling kecil didapatkan dengan komposisi binder thermoplastik sebesar $30 \% \mathrm{wt}$ dan $70 \% \mathrm{wt}$ pasir dengan nilai 46,02 $\mathrm{MPa}$.

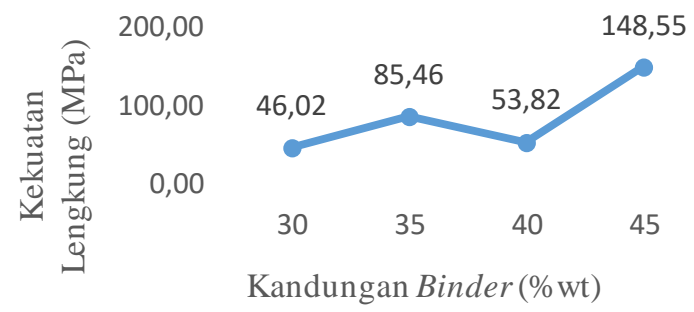

Gambar 5. Grafik nilai kekuatan bending komposit

Bahan bangunan seperti beton, ubin, dan dinding biasanya memiliki karakteristik yang kaku sehingga dapat memiliki ketangguhan yang kurang baik [3]. Dengan kenaikan flexural strength akan menguntungkan untuk aplikasi dari material bangunan karena akan menurunkan kekakuan yang akan menyebabkan ketangguhan yang lebih baik dari bahan bangunan [3].

\section{B. Pengujian kompresi}

Dari hasil pengujian didapatkan bahwa adanya binder thermoplastik dalam komposit, mempengaruhi nilai kekuatan kompresi. Kekuatan bending ditunjukkan pada Tabel 3.

Tabel 3.

Hasil uji kompresi

\begin{tabular}{cccc}
\hline \hline No. & $\begin{array}{c}\text { Binder } \\
(\% \mathrm{wt})\end{array}$ & $\begin{array}{c}\text { Agregat } \\
\text { Pasir } \\
(\% \mathrm{wt})\end{array}$ & $\begin{array}{c}\text { Kekuatan Kompresi } \\
(\mathrm{MPa})\end{array}$ \\
\hline 1 & 30 & 70 & 13,72 \\
2 & 35 & 65 & 7,84 \\
3 & 40 & 60 & 12,54 \\
4 & 45 & 55 & 15,68 \\
\hline \hline
\end{tabular}

Gambar 6 menunjukkan bukti bahwa dengan penambahan binder berupa thermoplastik dapat meningkatkan kekuatan kompresi dari komposit untuk aplikasi material bangunan. Kekuatan kompresi paling tinggi didapatkan dengan komposisi $45 \%$ wt binder thermoplastik dan 55\% wt pasir dengan kekuatan kompresi sebesar 15,68 MPa. Sedangkan kekuatan kompresi paling rendah didapatkan pada komposisi komposit dengan komposisi 35\%wt binder dan 65\%wt pasir dengan kekuatan kompresi sebesar 7,84 MPa.

Kenaikan kekuatan kompresi pada material komposit ini disebabkan oleh kekuatan ikatan antar interface polimer dan agregat (pasir) yang meningkat dengan adanya penambahan binder thermoplastik (Asthana, 2004). Karakteristik polimer yang mengisi pori juga dapat meningkatkan kekuatan mekanik dari material komposit [3].

Dari pengujian kompresi yang telah dilakukan dapat diambil kesimpulan hampir semua spesimen memenuhi standar SNI untuk kekuatan kompresi untuk aplikasi paving block. Dalam hal ini adalah paving block kategori $\mathrm{C}$ untuk pejalan kaki dan D untuk pelataran taman yang memiliki standar kekuatan kompresi minimal sebesar 12,5 MPa untuk kategori $\mathrm{C}$ dan 8,5 MPa untuk kategori D.

Material komposit yang telah diproduksi ini juga telah memenuhi kriteria untuk beton ringan dengan massa jenis sebesar $1000-2000 \mathrm{~kg} / \mathrm{m}^{3}$. Dan material komposit yang telah diproduksi ini telah memenuhi standar kekuatan kompresi untuk klasifikasi beton struktural ringan dengan kekuatan kompresi antara 6,89-17,24 Mpa.

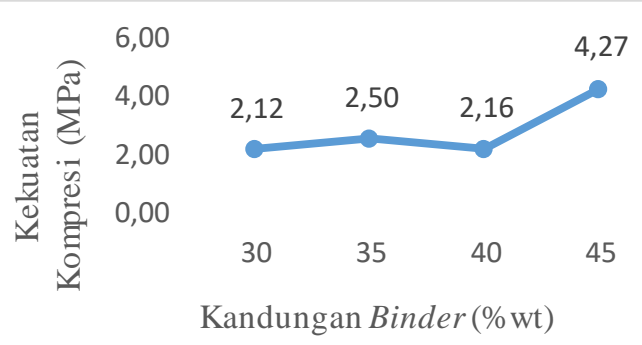

Gambar 6. Hasil uji kompresi 


\section{Pengujian densitas}

Dari hasil pengujian dengan adanya penambahan binder thermoplastik dalam komposit mempengaruhi nilai kekuatan bending dari komposit tergantung dari banyaknya komposisi binder thermoplastik pada komposit. Hasil uji bending ditunjukkan pada Tabel 4.

Tabel 4.

Hasil uji densitas

\begin{tabular}{cccc}
\hline \hline No. & $\begin{array}{c}\text { Binder } \\
(\% \mathrm{wt})\end{array}$ & $\begin{array}{c}\text { Agregat } \\
\text { Pasir } \\
(\% \mathrm{wt})\end{array}$ & $\begin{array}{c}\text { Density } \\
(\mathrm{g} / \mathrm{cm} 3)\end{array}$ \\
\hline 1 & 30 & 70 & 1,54 \\
2 & 35 & 65 & 1,78 \\
3 & 40 & 60 & 1,52 \\
5 & 45 & 55 & 0,79 \\
\hline \hline
\end{tabular}

Hasil pengujian menunjukkan dengan penambahan binder thermoplastik dapat mempengaruhi nilai massa jenis komposit. Massa jenis paling tinggi ditemukan pada spesimen nomor 2 yang terbuat dari $35 \%$ wt binder thermoplastik dan $65 \%$ wt pasir dengan nilai $1,78 \mathrm{~g} / \mathrm{cm}^{3}$. Sedangkan yang paling kecil ditemukan pada spesimen nomor 4 yang terbuat dari $45 \% \mathrm{wt}$ binder thermoplastik dan $55 \%$ pasir dengan massa jenis sebesar $0,79 \mathrm{~g} / \mathrm{cm}^{3}$.

Gambar 7 menunjukkan nilai massa jenis komposit dengan adanya penambahan binder thermoplastik dalam grafik. Hal tersebut menunjukkan bahwa penambahan binder thermoplastik cenderung menurunkan nilai massa jenis dari material komposit untuk aplikasi material bangunan.

Massa jenis akan turun seiring dengan bertambahnya komposisi polimer. Hal ini dikarenakan massa jenis yang rendah dari polimer. Polimer juga dapat menjebak udara yang ada di dalam campuran [4].

Material komposit yang telah diproduksi ini memenuhi kriteria massa jenis untuk aplikasi beton ringan dengan massa jenis antara $1000-2000 \mathrm{~kg} / \mathrm{m}^{3}$. Namun untuk spesimen nomor 4 dan 5 tidak memenuhi kriteria massa jenis karena memiliki massa yang lebih kecil dari standard yang telah ditentukan.
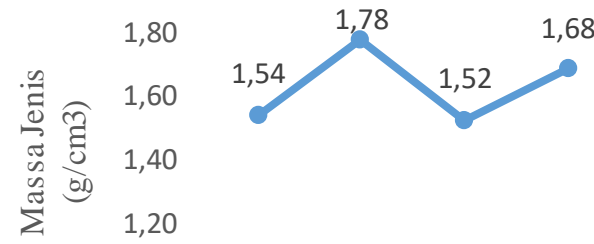

$\begin{array}{llll}30 & 35 & 40 & 45\end{array}$

Kandungan Binder (\%wt)

Gambar 7. Hasil uji densitas

\section{Uji penyerapan air}

Tabel 5 menunjukkan nilai absorbability dari material komposit dalam bentuk persentase (\%). Dari hasil pengujian didapatkan dengan penambahan binder berupa thermoplastik dapat mempengaruhi nilai absorbability dari komposit. Nilai absorbability paling besar didapatkan pada spesimen 5 dengan komposisi $45 \%$ binder thermoplastik dan 55\% pasir dengan nilai absorbability $4,27 \%$. Sedangkan nilai absorbability paling kecil didapatkan pada spesimen 8 dengan komposisi $100 \%$ binder thermoplastik dengan nilai absorbability sebesar 0,53\%.

Tabel 5.

Hasil uji penyerapan air

\begin{tabular}{cccc}
\hline \hline No. & $\begin{array}{c}\text { Binder } \\
(\% \mathrm{wt})\end{array}$ & $\begin{array}{c}\text { Agregat } \\
\text { Pasir } \\
(\% \mathrm{wt})\end{array}$ & $\begin{array}{c}\text { Absorbability } \\
(\%)\end{array}$ \\
\hline 1 & 30 & 70 & 2,12 \\
2 & 35 & 65 & 2,50 \\
3 & 40 & 60 & 2,16 \\
4 & 45 & 55 & 1,89 \\
\hline \hline
\end{tabular}

Gambar 8 menunjukkan nilai absorbability dari komposit dalam bentuk grafik. Hal ini menunjukkan bahwa dengan penambahan binder yang terbuat dari thermoplastik dapat menurunkan nilai absorbability.

Penurunan nilai absorbability diakibatkan oleh karakteristik polimer yang mengisi pori antar partikel agregat (pasir) [5]. Selain itu sifat alami dari polimer yang hidrofobik juga mengakibatkan turunnya nilai absorbability [6].

Nilai absorbability yang kecil dapat menguntungkan untuk aplikasi bahan bangunan karena dapat mengurangi resiko yang disebabkan oleh penetrasi air ke dalam rongga-rongga dari material bangunan yang dapat menyebabkan kerusakan seperti retakan dan tumbuhnya mikroorganis me yang tidak diinginkan.

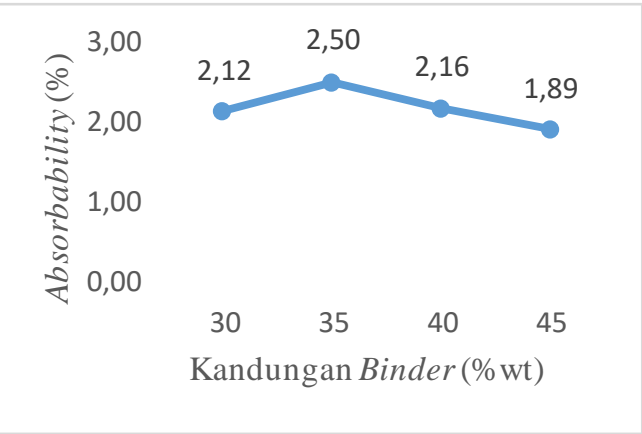

Gambar 8. Hasil pengujian serap air

\section{E. Scanning Electron Microscope (SEM)}

Morfologi dari spesimen komposit ditunjukkan dengan fotomikrograph Scanning Electron Microscope. Selain morfologi, melalui fotomikrograph SEM juga bisa didapatkan informasi persebaran porositas, dan ukuran porositas. SEM menganalis a interface antara binder thermoplastik dan agregat berupa pasir.

Pengamatan morfologi dilakukan di Jurusan Teknik Material dan Metalurgi Fakultas Teknologi Industri Institut Teknologi Sepuluh Nopember Surabaya dengan perbesaran sebesar 500x. Berdasarkan Gambar 9 terlihat bahwa ada perbedaan morfologi dari masing-masing spesimen komposit. Hal ini dikarenakan komposisi dari binder thermoplastik dan agregat pasir yang berbeda pada tiap spesimen tersebut. Gambar (a) menunjukkan morfologi spesimen dengan komposisi 20\%wt LDPE, 15\%wt PET, dan $45 \%$ pasir. Gambar (b) menunjukkan morfologi spesimen dengan komposisi $45 \%$ wt LDPE dan $55 \%$ pasir. Dan gambar (c) menunjukkan morfologi spesimen dengan 
komposisi 45\%wt PET dan 55\% pasir. Pada gambar (a) ditemukan keberadaan void yang lebih banyak dibandingkan pada gambar (b) dan juga (c). Hal ini dapat berpengaruh pada sifat mekanik dari komposit [4].
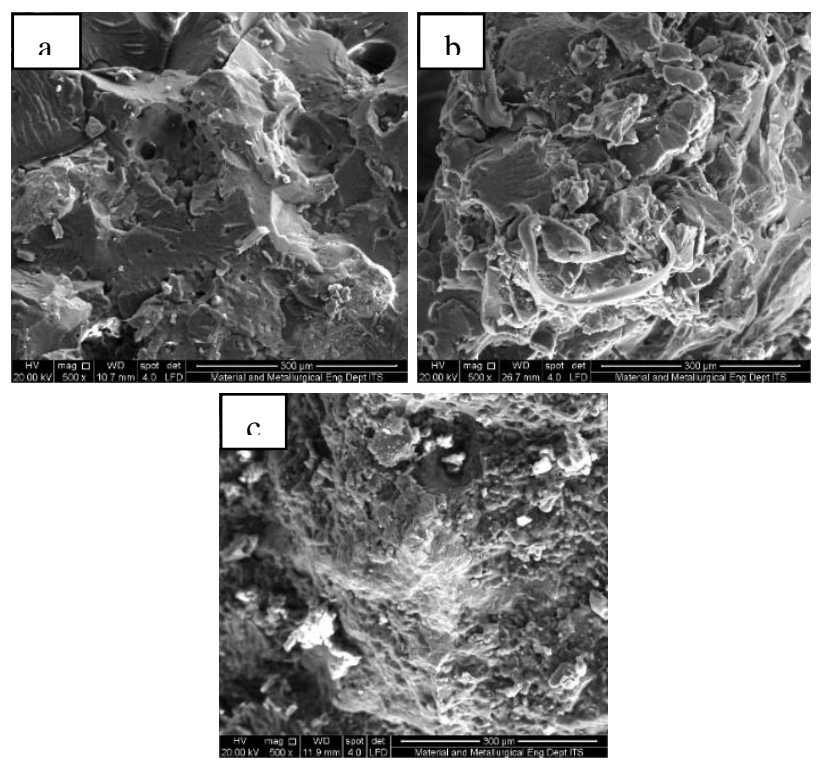

Gambar 9. Hasil uji SEM dengan perbesaran 500x : (a) Spesimen 2 (b) Spesimen 5 (c) Spesimen 6

Morfologi dari komposit yang dibuat dengan binder thermoplastik dan agregat pasir terlihat lebih jelas dengan perbesaran yang lebih besar. Morfologi dari spesimen 2 pada gambar (a) terlihat memiliki void dengan ukuran yang besar. Perbedaan pada persebaran dan ukuran void pada dasarnya diakibatkan pada proses pembuatan biasanya pada saat pencampuran dan juga penuangan. Spesimen nomor 5 yang ditunjukkan pada gambar (b) memiliki bonding yang rendah antar interface daribinder thermoplastik dan juga agregat pasir. Sedangkan pada gambar (c) terlihat lebih merata pada semua bagian dan interface antara binder dan agregat pasir yang lebih berdekatan satu sama lain.

Tabel 6. Nilai \% Void Spesimen Komposit

\begin{tabular}{cc}
\hline \hline Spesimen & \%Void \\
\hline 2 & $11,56 \%$ \\
5 & $6,69 \%$ \\
6 & $2,00 \%$ \\
\hline \hline
\end{tabular}

Jika dikaitkan dengan sifat mekanik dan sifat fisik dari komposit yang dihasilkan spesimen nomor 6 pada gambar (c) memiliki kekuatan kompresi yang paling tinggi dibandingkan semua spesimen komposit yang telah dibuat. Bukti juga diperkuat oleh nilai \%void dari material komposit pada Tabel 6. Spesimen nomor 2 memiliki nilai \%void paling besar yaitu $11,56 \%$ yang mengakibatkan sifat mekanik yang kurang baik. Sedangkan pada sampel $6 \%$ void paling kecil yaitu sebesar $2 \%$ yang mengakibatkan sifat mekanik nya paling baikSpesimen nomor juga juga memiliki massa jenis yang lebih tinggi dan nilai absorbability yang lebih rendah dibandingkan spesimen nomor 5 pada gambar (b). Maka dari itu, dapat dikatakan bahwa spesimen nomor 6 adalah material yang lebih compact dibandingkan spesimen lainnya yang dilihat secara mikroskopis menggunakan SEM.

\section{F. Analisa Hasil FTIR}

Pengujian dengan alat FTIR dilakukan untuk menemukan gugus fungsi dari material komposit dan membangdingkan dengan gugus fungsi dari material penyusunnya yaitu LDPE dan PET. Pengujian FTIR dilakukan dengan mesin FTIR milik Jurusan Teknik Material dan Metalurgi FTI ITS.

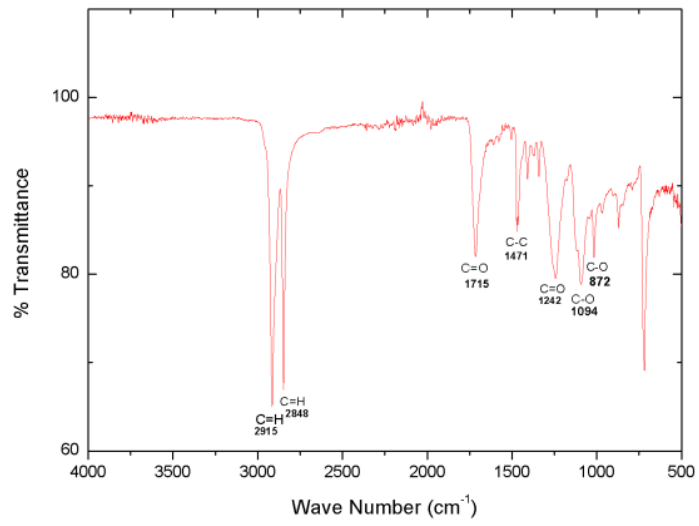

Gambar 11. Hasil uji FT IR komposit dengan komposisi 20\%wt LDPE, 15\%wt PET, dan 65\% Pasir

Tabel 7.

Daerah serapan komposit dengan komposisi 20\%wt, LDPE, 15\%WT PET, dan $65 \%$ wt Pasir

\begin{tabular}{ccc}
\hline \hline Wavenumber & Ikatan & Gugus \\
\hline 2915 & $\mathrm{C}=\mathrm{H}$ & Alkana \\
2848 & $\mathrm{C}=\mathrm{H}$ & Alkana \\
1715 & $\mathrm{C}=\mathrm{O}$ & Karboxil \\
1471 & $\mathrm{C}=\mathrm{H}$ & Alkana \\
1242 & $\mathrm{C}-\mathrm{O}$ & Ester \\
1094 & $\mathrm{C}-\mathrm{O}$ & Ester \\
872 & $\mathrm{C}-\mathrm{H}$ & Alkana \\
\hline \hline
\end{tabular}

Gambar 11 menunjukkan hasil uji FTIR dari spesimen nomor 2 dengan komposisi 20\%wt LDPE, 15\%wt PET, dan 65\%wt pasir. Sampe dianalisa pada wavenumber antara $4000-500 \mathrm{~cm}^{-}$ 1. Hasil menunjukkan ikatan $\mathrm{C}=\mathrm{H}$ dari polyethylene pada puncak gelombang tertinggi yaitu $2915 \mathrm{~cm}^{-1}, 2848 \mathrm{~cm}^{-1}$, dan $1471 \mathrm{~cm}^{-1}$.

Terdapat juga ikatan-ikatan dari thermoplastik PET dengan ikatan karboxil $\mathrm{C}=\mathrm{O}$ dari $\mathrm{PET}$ pada gelombang $1715 \mathrm{~cm}^{-1}$. Ikatan ester C-O juga ditemukan pada gelombang $1242 \mathrm{~cm}^{-1}$ dan $1094 \mathrm{~cm}^{-1}$. Dan yang terakhir ditemukan ikatan alkana $\mathrm{C}-\mathrm{H}$ milik PET pada gelombang $872 \mathrm{~cm}^{-1}$

Melalui pengujian FTIR diketahui bahwa terdapat pergeseran daerah serapan pada beberapa gelombang dibandingkan dengan pada LDPE dan PET murni. Hasil dari pengujian FTIR juga tidak ditemukan adanya puncak baru yang berarti tidak terbentuk adanya ikatan baru pada proses pembuatan komposit dengan binder thermoplastik LDPE dan PET. 
Tabel 8.

Daerah serapan PET

\begin{tabular}{ccc}
\hline \hline Wavenumber & Ikatan & Gugus \\
\hline 2958 & H-C-H & Alkana \\
2885 & H-C-H & Alkana \\
1948 & $\mathrm{C}-\mathrm{H}$ & Aromatic Ring \\
1710 & $\mathrm{C}=\mathrm{O}$ & Karbonil \\
1458 & $\mathrm{C}=\mathrm{H}$ & Alkana \\
1100 & $\mathrm{C}-\mathrm{O}$ & Ester \\
1017 & $\mathrm{C}-\mathrm{O}$ & Ester \\
870 & $\mathrm{C}-\mathrm{H}$ & Alkana \\
743 & $\mathrm{C}-\mathrm{H}$ & Aromatic Ring \\
\hline \hline
\end{tabular}

Tabel 9.

Daerah serapan LDPE

\begin{tabular}{ccc}
\hline \hline Wavenumber & Ikatan & Gugus \\
\hline 2919 & $\mathrm{C}=\mathrm{H}$ & Alkana \\
2851 & $\mathrm{C}=\mathrm{H}$ & Alkana \\
1472 & $\mathrm{C}=\mathrm{H}$ & Alkana \\
1377 & $\mathrm{C}-\mathrm{O}$ & Ester \\
1366 & $\mathrm{C}-\mathrm{O}$ & Ester \\
1306 & $\mathrm{C}-\mathrm{O}$ & Ester \\
1176 & $\mathrm{C}-\mathrm{O}$ & Ester \\
731 & $\mathrm{C}-\mathrm{H}$ & Metana \\
\hline \hline
\end{tabular}

\section{KESIMPULAN}

Penambahan binder thermoplastik berupa LDPE dan PET hasil pengolahan sampah plastik mempengaruhi sifat mekanik dan sifat fisik dari material komposit. Penambahan binder thermoplastik cenderung meningkatkan sifat mekanik dan sifat fisik dari material komposit. Material komposit yang telah dibuat menggunakan binder thermoplastik berupa LDPE dan PET hasil pengolahan sampah plastik memenuhi kriteria untuk material bangunan untuk aplikasi beton ringan struktural dan paving block kategoriC untukaplikasi pejalan kakidan Duntuk aplikasi pelataran taman.

\section{UCAPAN TERIMAKASIH}

Penulis berterimakasih banyak kepada Bapak Sigit Tri Wicaksono S.Si., M.Si., Ph.D sebagai inisiator dari "Plastic Waste Project" sebagai insipirasi utama untuk penyusunan jurnal ini.

\section{DAFTAR PUSTAKA}

[1] S. Tapkire, G., \& Parihar, "Recycled Plastic Used in Concrete Paving Block," Int. J. Res. Eng. Technol., 2014.

[2] D. W. Fowler, Polymers in concrete: a vision for the 21 st century. Texas: Elsevier, 1999.

[3] M. Frigione, Concrete with Polymers. Italy: University of Salento, 2010.

[4] K. Jafari, Experimental and analytical evaluation of rubberized polymer concrete. iran: Elsevier, 2017.

[5] K. Asthana, "Development of polymer modified cementitious (polycem)," Constr. Build. Mater., vol. 18, pp. 639-643, 2004.

[6] D. H. (n. d. ). Justnes, Polymer Cement Concrete (PCC) of Interest for Concrete Block Paving. Trondheim, Norway: SINTEFStructures and Concrete. 